\title{
Differential effect of hesperidin on Th1, Th2, Th17, and proinflammatory cytokines production from splenocyte of Schistosoma mansoni-infected mice
}

\author{
GAMAL ALLAM $M^{1,2}$, ABDELAZIZ S.A. ABUELSAAD $D^{1,2}$ \\ ${ }^{1}$ Department of Microbiology, College of Medicine, Taif University, Taif, Saudi Arabia \\ ${ }^{2}$ Department of Zoology, Faculty of Science, Beni-Suef University, Beni-Suef, Egypt
}

\begin{abstract}
The present study was conducted to evaluate the potential effect of hesperidin on the regulating Th1, Th2, Th17, and the proinflammatory cytokines production from splenocyte of acute murine schistosomiasis. Each mouse was infected with 100 cercariae of Schistosoma (S.) mansoni and at 8 weeks postinfection, mice were sacrificed, splenocytes were prepared and cultured in the presence of either soluble adult worm antigen (SWAP) or soluble egg antigen (SEA) of S. mansoni with either 50 or $100 \mu M$ hesperidin. Hesperidin, in both tested concentrations, significantly augmented interleukin (IL) 4 $(p<0.05), I L-10(p<0.01)$, and interferon $\gamma(I F N-\gamma)(p<0.05)$ production in response to SAWP and $S E A$ stimulation. However, IL-13, IL-17, IL-1, and tumor necrosis factor $\alpha(T N F-\alpha)$ production were significantly $(p<0.01)$ reduced. Interleukin 12 production was not significantly $(p>0.05)$ changed with hesperidin treatment at $50 \mu \mathrm{M}$, while $100 \mu \mathrm{M}$ concentration of hesperidin significantly reduced IL-12 production in response to SWAP $(p<0.05)$ and SEA $(p<0.01)$ stimulation. The results suggested that hesperidin preferentially modulated in vitro production of Th1, Th2, Th17, and proinflammatory cytokines and this could reduce immunopathology of schistosomiasis.
\end{abstract}

Key words: hesperidin, schistosomiasis, Th1, Th2, Th17, proinflammatory cytokines production.

(Centr Eur J Immunol 2013; 38 (1): 29-36)

\section{Introduction}

In Schistosoma (S.) mansoni infection, the outcome of the immune response determines the balance between protective immunity and immunopathology [1]. The morbidity in $S$. mansoni infection arises from the granulomatous response to eggs that become trapped in the host tissues with subsequent fibrosis. Granuloma formation is dependent on $\mathrm{CD}^{+} \mathrm{T}$ cell responses [2, 3], while schistosomiasis is associated with an imbalance in T helper 1 (Th1)/Th2 cytokines [4]. Differentiation of CD4+ T cells into Th1 or Th2 lymphocyte population depends to a great extent upon the relative abundance of various cytokines during the priming of the antigen-specific lymphocyte population by antigen-presenting cells [5, 6]. Meanwhile, interleukin (IL) 12 and IL-4, the key promoters of Th1 and Th2 cell popula- tions respectively, both are mutually antagonistic. Interleukin 4 is capable of inhibiting the expression of the $\beta 2$ subunit of the IL-12 receptor [7] while IL-12 is responsible for the suppression of IL-4 production in a interferon $\gamma$ (IFN- $\gamma$ )-dependent manner [8]. Therefore, modulation of both Th1 and Th2 responses could down regulate the granulomatous inflammation and consequently reduce morbidity from schistosomiasis.

In the course of an infection, Th1 response is dominant in the first 3-5 weeks of infection during the migration and the maturation of parasites while Th2 cytokine expression becomes dominant shortly after egg laying begins; with IL-4, IL-5, IL-10, and IL-13 are the principal cytokines secreted by lymphoid cells after stimulation with schistosome egg antigens [9]. The secretion of Th1 cytokines, IFN- $\gamma$ and IL-2, is concurrently down-regulated at the time

Correspondence: Gamal Allam, Current address: Department of Microbiology, College of Medicine, Taif University, Taif, Saudi Arabia; Permanent address: Department of Zoology, Faculty of Science, Beni-Suef University, Beni-Suef, Egypt, tel. +966 56 9288913, fax +966 2 7250528, e-mail: g.allam@tu.edu.sa; gm_allam@yahoo.com 
the Th2 response reaches their peak [10]. There is a current clear consensus that $\mathrm{Th} 2$ responses contribute substantially in mediating the formation of the egg induced granulomas, as an abrogation of the type 2 responses by ablation of STAT6 [11] or IL-4 $\alpha$ receptor [12] expression greatly reduces the granuloma formation. Th2 activation appears to be necessary in protecting the host from the lethal hepatic and intestinal damage during acute infection [13] and keeping Th1 inflammatory immunopathology in check [14]. In contrary, immunization studies suggested that these Th2 responses might not provide protective immunity; instead, the Th1 immune response appeared to be important in the induction of resistance against $S$. mansoni in the murine model $[15,16]$. Several studies have reported that the protection in radiation-attenuated vaccine model of murine schistosomiasis is dependent on the Th1-associated humoral and cell-mediated immune responses [17-19]. Nevertheless, in the absence of Th1-type responses a reduction in worm burdens was observed, suggesting that the Th2-type responses might also possess a role in protection [20, 21]. Accordingly, a balance between Th1 and Th2 response is an important factor to maintain protective immunity and to reduce the pathological changes induced by schistosomiasis.

Recently, Th17 cell was involved in the research of adjustment net of cytokines in schistosomiasis in an animal model [22]. Interleukin 17 producing cells were identified as a distinct lineage of CD4+ T cells with a potent proinflammatory properties [23, 24]. Interleukin 17-producing cells were first shown to mediate the immunopathology in several autoimmune diseases such as allergic encephalomyelitis, collagen induced arthritis, and inflammatory bowel disease [25-28]. In severe schistosomiasis, pronounced immunopathology correlated with an increase in IL-17 production by granuloma cells in the lesions of the infected animals was observed [29, 30]; such pathology was reduced by in vivo neutralization of IL-17 [29]. In these circumstances, activated dendritic cells (DC) could initiate an innate proinflammatory cascade leading to the differentiation of pathogenic Th17 cells in response to schistosome egg antigens [31]. Such interactions were shown to be conducive to the differentiation of $\mathrm{Th} 2$ [32] or T regulatory cell responses [33, 34] however, the data bout IL-17 as an adjusted factor in schistosomiasis, was still insufficient. Therefore, the balance of Th1-, Th2-, and Th17-type lymphocyte populations in the host after exposure to infection is crucial to the development of protective immunity or immunopathology.

Hesperidin (HES, 5,7,3'-trihydroxy-4'-methoxy-flavanone 7-rhamnoglucoside, CAS number: 520-26-3) a flavanone-type flavonoid, is abundant in citrus fruits and has been reported to possess many biological activities: antifungal and antiviral activities [35, 36], inhibition of cell cycle progression in human pancreatic cells [37], reduction of reactive oxygen species [38] and triggering an in vitro caspase dependent apoptosis in human polymorphonuclear neutrophils [39], cytotoxic effects on human colon cancer cells accompanied with DNA fragmentation and caspase3 activation [40], an antioxidant effect [41, 42], anti-inflammatory effects on rodent cell lines and human cell lines [43, 44], suppression of mRNA and protein expression of cyclooxygenase-2 (COX-2) in LPS-induced macrophages $[45,46]$, reduction of tumor necrosis factor $\alpha$ (TNF- $\alpha)$ production and inhibition of infection-induced lethal shock [47], downregulation of mRNA and protein expression of TNF- $\alpha$, IL-1 $\beta$, IL-6, IL-8, IL-12, and iNOS [46, 48-52], suppression of eosinophil infiltration, allergic airway inflammation, IL-13, IL-5, and IL-17 production in mouse model of allergic asthma [53, 54], enhancement the production of IL-4, and IL-10 in bronchoalveolar lavage fluid of mouse with acute lung inflammation [48], and increased IFN- $\gamma$ release from pollen-stimulated PBMC of patients with seasonal allergic rhinitis to pollen [55]. However, there no studies was reported on the effect of HES on cytokine profile and Th1/Th2 bias of $S$. mansoni-infected mice. The aim of the current study was to evaluate the in vitro ability of HES to regulate proinflammatory, Th1-, Th2-, and Th17-type cytokines production using murine model of $S$. mansoni.

\section{Material and methods}

\section{Mice and parasite}

Eight-weeks-old MF1 male mice were purchased from the Biological Supply Centre, King Fahd Centre for Medical Researches, College of Medicine, King Abdulaziz University, Jeddah, Saudi Arabia. Mice were housed in stainless-steel cages under strict hygienic conditions at $25-28^{\circ} \mathrm{C}$, 8-12 h light and free access to feed and water. S. mansoni (John Bruce Egyptian strain) cercariae were collected by illumination of the infected Biomphalaria alexandrina snails under a 60-watt lamp for $2 \mathrm{~h}$ as previously described [56].

\section{Infection}

Mice were infected by tail immersion method according to Bruce and Radke [57] with some modifications. Briefly, mice were individually placed in mouse retraining chambers, allowing the tail outside the chamber. After cleaning the tail with dechlorinated tap water, it was inserted into a vial containing 100 cercariae in $2 \mathrm{ml}$ dechlorinated tap water and located into an exposure board. Mice were left in contact with the infective cercariae for $2 \mathrm{~h}$, and then removed from the chamber and tails were allowed to dry. The remaining cercariae were counted and mice receiving less than $95 \%$ of the cercariae were excluded from the experiment.

\section{Reagents}

Hesperidin (HES, purity $\geq 97.0 \%$ ) was dissolved in dimethylsulfoxide (DMSO) and then diluted with Roswell 
Park Memorial Institute (RPMI) 1640 medium (Invitrogen) at a final DMSO concentration $\leq 0.05 \%(\mathrm{v} / \mathrm{v})$. All reagents were from Sigma Chemical Co. (St. Louis, MO, USA) unless otherwise stated.

\section{Antigens \\ Soluble adult worm antigen (SWAP) and soluble egg antigen (SEA) of $S$. mansoni were purchased from Schis- tosome Biological Supply Center, Theodore Bilharz Research Institute (TBRI, Imbaba, Giza, Egypt). Antigen preparations were suspended in sterile $0.01 \mathrm{M}$ phosphate buffered saline (PBS), $\mathrm{pH} 7.2$, protein content was meas- ured by Lowry's method [58]. Antigens were diluted with sterile RPMI- 1640 medium and stored at $-80^{\circ} \mathrm{C}$ as aliquots until used.}

\section{Splenocyte preparation}

Spleens were removed from infected mice aseptically after 8 weeks of infection. Single cell suspensions were prepared as described previously [59] with some modifications. Briefly, cells suspension were obtained by forcing tissues through sterile 70-mm nylon mesh (Becton Dickinson) and washed one time with ice-cold RPMI-1640 medium. Erythrocytes were lysed from the dispersed spleen cell suspensions by hypotonic shock followed by extensive washing with RPMI-1640 medium. After cells counting and viability percentages calculation by using trypan blue exclusion method, cells were resuspended in appropriate volume of RPMI-1640 medium supplemented with $10 \%$ heat-inactivated fetal calf serum (FCS), $100 \mathrm{U} / \mathrm{ml}$ penicillin, $100 \mu \mathrm{g} / \mathrm{ml}$ streptomycin, $2 \mathrm{mM}$ L-glutamine and $1 \mathrm{mM} \mathrm{Na}$ pyruvate.

\section{Cytokine production}

The effect of HES on different cytokines (IL-1, IL-4, IL-10, IL-12, IL-13, IL-17, TNF- $\alpha$ and IFN- $\gamma$ ) production in response to SAWA and SEA stimulation was tested. Splenocytes from infected mice were suspended in complete tissue culture medium (CM) at a final concentration of $1.5 \times 10^{6}$ cells $/ \mathrm{ml}$. Splenocytes from each mouse were cultured in triplicates, $1.5 \times 10^{5}$ cells/well, in a total volume of $200 \mu 1 /$ well into flat-bottom 96 -well plates (Falcon) containing either sterile SAWA $(2 \mu \mathrm{g} /$ well $)$ or SEA $(1 \mu \mathrm{g}$ / well) with either 50 or $100 \mu \mathrm{M}$ HES, and HES free cultures containing $\leq 0.05 \%(\mathrm{v} / \mathrm{v})$ DMSO $(\mathrm{CM})$ used as control. Then plates were incubated either at $24 \mathrm{~h}$ (for IL-4 production) or $72 \mathrm{~h}$ (for assessment of other cytokines) at $37^{\circ} \mathrm{C}$ in humidified $5 \% \mathrm{CO}_{2}$ atmosphere. At the end of the incubation periods, cell-free supernatants were harvested and stored at $-80^{\circ} \mathrm{C}$ until used for cytokine determination assays.

\section{Cytokine determination}

The amount of IL-1 $\beta$, IL-4, IL-10, IL-12, IL-13, IL-17A, TNF- $\alpha$, and IFN- $\gamma$ were quantified in culture supernatants by sandwich enzyme linked immunosorbent assays
(ELISA). Briefly, high protein binding ELISA plates (Nunc, Denmark) were coated with $2 \mu \mathrm{g} / \mathrm{ml}$ of capture monoclonal antibody (eBioscience, Birmingham, USA) against the target cytokine for at least $18 \mathrm{~h}$ at $4^{\circ} \mathrm{C}$ in $0.05 \mathrm{M}$ carbonate/bicarbonate buffer, $\mathrm{pH}$ 9.6. After blocking the free spots of the wells with $5 \%$ non-fat milk, culture supernatants were dispensed and incubated for $2 \mathrm{~h}$ at room temperature (RT). Plates were washed, then $1 \mu \mathrm{g} / \mathrm{ml}$ of the detecting biotin labeled antibodies (eBioscience) was added and incubation for $1 \mathrm{~h}$ at RT. Unbound biotine was removed by 5 times washing, $100 \mu \mathrm{l} /$ well of $1: 4000$ diluted peroxidase-labeled streptavidin (eBioscience) was added and plates were incubated for $1 \mathrm{~h}$ at RT. Ortho-phenylenediamine (OPD) was then added $(100 \mu \mathrm{l} /$ well $)$ and the plates were placed in the dark at RT for $30 \mathrm{~min}$. Finally, the $2 \mathrm{~N} \mathrm{H}_{2} \mathrm{SO}_{4}(100 \mu \mathrm{l} /$ well $)$ was added and the absorbance was measured at $492 \mathrm{~nm}$ using microplate reader (BioTech, CA, USA). Cytokine concentrations were determined by reference to standard curves construction with known amounts of mouse recombinant IL-1 $\beta$, IL-4, IL-10, IL-12p70, IL-13, IL-17A, TNF- $\alpha$, or IFN- $\gamma$ (eBioscience).

\section{Statistical analysis}

The statistical tests were performed with the SPSS (version 16) software. Significant differences were determined by one-way analysis of variance (ANOVA) and applying Tukey's test for multiple comparisons with a level of significance set at $p<0.05$.

\section{Results and discussion}

Cytokines play an important role in the immunological pathogenesis of schistosomiasis. The disease is associated with an imbalance in Th1/Th2 cytokines [4]. Therefore, modulation of Th1, Th2, and Th17 responses as well as proinflammatroy cytokines could downregulate granulomatous inflammation and consequently controls the outcome of immunopathology in schistosomiasis. To investigate the regulatory role of HES on cytokine secretion during acute schistosomiasis, splenocytes isolated from 8 weeks $S$. mansoni infected mice and cultured with either 50 or $100 \mu \mathrm{M}$ HES in response to SWAP and SEA of S. mansoni. Cytokine production was quantified by using sandwich ELISA. The tested HES concentrations were chosen according to Yeh et al. [48], who showed that $50 \mu \mathrm{M}$ HES suppressed the in vitro expression of IL-8, TNF- $\alpha$, IL- $1 \beta$, IL-6, IL-12, ICAM-1, and VCAM-1 on epithelial cell line (A549) and myelomonocytic cell line (THP-1).

\section{Effect of hesperidin on Th2 cytokine production}

Data of the present study showed that both tested concentrations $(50$ and $100 \mu \mathrm{M})$ of HES significantly $(p<0.05)$ increased the IL-4 production (Fig. 1A). Interleukin 4 operates as the key cytokine driving the Th2 response [60]. In the absence of IL-4, some strains of mice overproduce sev- 
eral pro-inflammatory mediators, including TNF- $\alpha$ and nitric oxide (NO), leading to an acutely fatal disease following infection [61]. Moreover, IL-4 has been shown to contribute in the induction of the protective immunity in the radiation attenuated vaccine model $[20,21]$. Therefore, IL-4 is an important cytokine for the regulation of immunopathology in schistosomiasis and may have a role in the protective immunity.

Similarly, data of the current study clearly showed that HES at 50 and $100 \mu \mathrm{M}$ concentrations significantly $(p<0.01)$ enhanced IL-10 production in response to both SWAP and ESA stimulation (Fig. 1B). Interleukin-10 is an important cytokine produced by a variety of cell types, including CD4+ and CD8+ T cells, monocytes/macrophages, mast cells, keratinocytes, eosinophils, and various tumor cells [62]. It was originally characterized by its ability to down-regulate Th1 response development, but is now
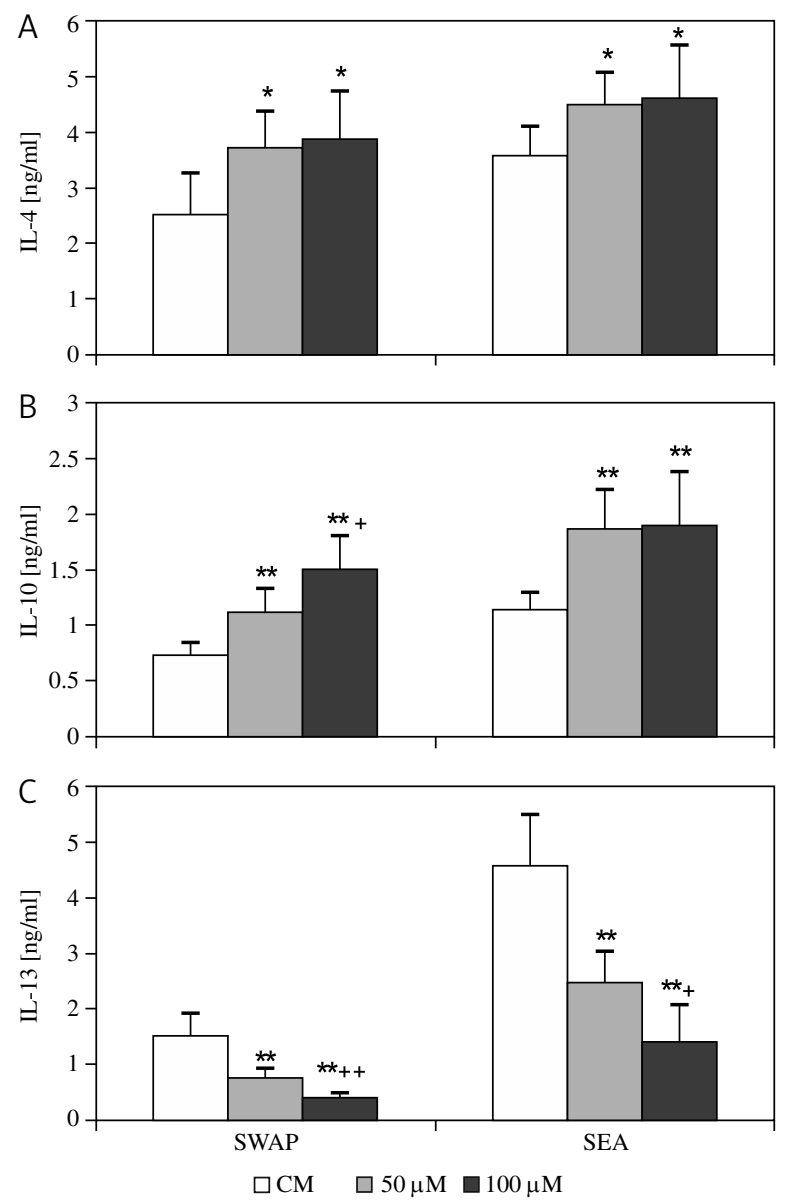

Fig. 1. The effect of hesperidin on Th2 cytokines production in response to SWAP and SEA stimulation. Columns represent mean of 5 individual mice, and the bars denote SD about the mean. Significant differences between culture medium (CM) and HES are denoted by asterisks $\left(* p<0.05,{ }^{* *} p<0.01\right)$ and between HES concentrations by plus $\left({ }^{+} p<0.05,{ }^{++} p<0.01\right)$ above the columns known to be a major immunoregulatory cytokine influencing Th cell development as well as the production of numerous proinflammatory cytokines [10]. It has been reported that IL-10 have a protective function during schistosomiasis, where up to $30 \%$ mortality was observed in IL-10deficient mice at the acute stage post-infection [63]. As in IL-4-deficient animals, liver damage caused by excess production of TNF- $\alpha$, nitric oxide and reactive oxygen intermediates appears to be the primary cause of mortality in IL10 deficient mice [64]. Therefore, upregulation of IL-10 could be downmodulate excessive production of inflammatory mediators and protect host tissues from further damage.

In contrast, IL-13 secretion significantly $(p<0.01)$ decreased with HES treatment in a dose dependent manner (Fig. 1C). Several studies have been pointed out the important role of IL-13 in the development of liver fibrosis in mice and humans [13, 65-67]. Mice deficient in IL-13 survived longer than similarly infected wild-type animals, and IL-13blocking studies have shown that this cytokine was the key mediator of fibrosis in schistosomiasis [68]. Although the average size of egg induced granulomas was unaltered to IL-13-deficient mice, the marked fibrotic changes were almost completely ablated in the absence of IL-13 even after several months of infection [66]. Fibrogenic effect of IL-13 was completely TGF- $\beta$ independent [69]. Consequently, down regulation of IL-13 might decrease tissues fibrosis accompanied with schistosomiasis.

\section{Effect of hesperidin on Th1 and Th17 cytokine production}

As depicted in Fig. 2A, HES at 50 and $100 \mu \mathrm{M}$ concentrations significantly $(p<0.05)$ enhanced IFN- $\gamma$ production in response to both SWAP and SEA stimulation. From the aforementioned data, HES stimulated IL-4 and IFN- $\gamma$ production from splenocytes of $S$. mansoni infected mice. Such increase in IFN- $\gamma$ with IL- 4 have also been reported in another model in which splenocytes treated with aqueous leaf extract of Morinda lucida, showed increased in both IFN- $\gamma$ and IL-4 production [70]. Interferon $\gamma$ plays a crucial role in the protective immunity against $S$. mansoni infection in radiation attenuated vaccine model [71, 72]. Previous reports suggested that IFN- $\gamma$ downregulated granuloma formation both in vitro and in vivo models [73, 74]. In addition, IFN- $\gamma$ has a potent antifibrogenic effect [75]. Therefore, modulation of IFN- $\gamma$ production has a beneficial effect and may relieve pathology of schistosomiasis and maintained protective immunity.

On the other hand, IL-17 highly significantly $(p<0.01)$ reduced with HES treatment in response to both SWAP and SEA antigens (Fig. 2B). It has been reported that in the natural and induced models of severe disease, pronounced immunopathology correlated with an increase in IL-17 production $[29,30]$. Hence, the reduction of IL-17 leaded to amelioration of schistosomiasis-induced pathology. 

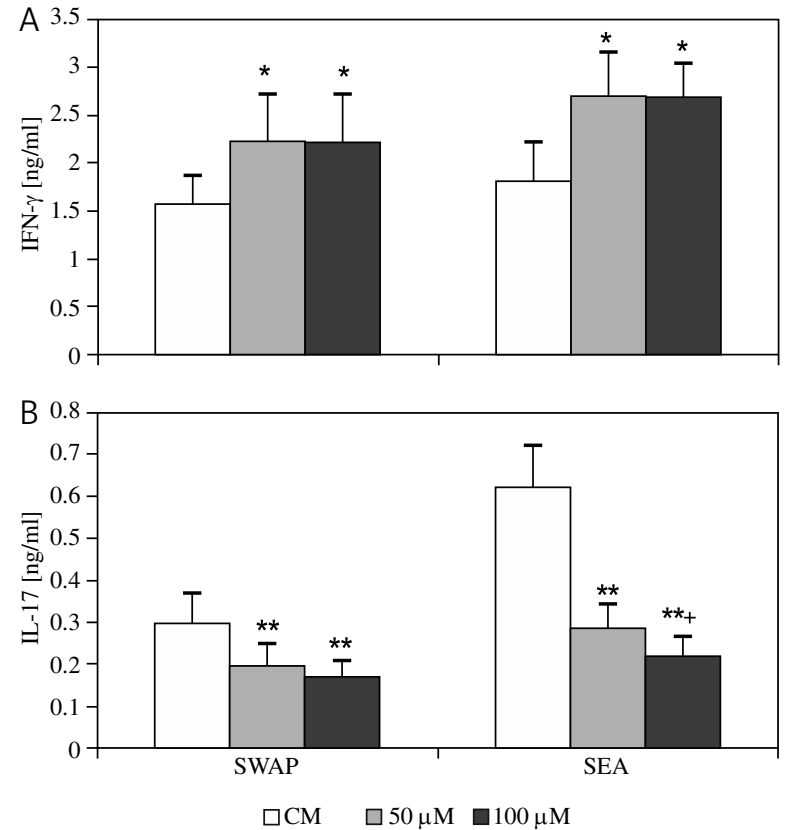

Fig. 2. The effect of hesperidin on Th1 (IFN- $\gamma$ ) and Th17 (IL-17) cytokines production in response to SWAP and SEA stimulation. Columns represent mean of 5 individual mice, and the bars denote SD about the mean. Significant differences between culture medium (CM) and HES are denoted by asterisks $(* p<0.05, * * p<0.01)$ and between HES concentrations by plus $\left({ }^{+} p<0.05\right)$ above the columns

\section{Effect of hesperidin on proinflammatory cytokine production}

To evaluate the potential antiinflammatory effect of HES, IL- $1 \beta$ was determined in culture soap of HES treated splenocytes in response to SWAP and SEA antigens. As depicted in Fig. 3A, HES at both tested concentrations significantly $(p<0.01)$ reduced IL- $1 \beta$ production in response to $S$. mansoni antigens stimulation in a dose dependent manner. The significance of this key proinflammatory cytokine in immunopathology of schistosomiasis was unclear and needs further investigations. However, in some strains of mice, IL-1 is known through its capacity to increase the synthesis of other cytokines and promote B cell maturation, differentiation, and antibody production [76, 77], elicited down-regulation of IFN- $\gamma$ in $S$. mansoni infection, and failed to enhance production of specific antibodies. Administration of IL-1 was associated with aggravation of the worm burden and/or egg load [78] therefore, the reduction of IL-1 is in favor of the host.

Data of the current study showed that HES significantly decreased IL-12 secretion at $100 \mu \mathrm{M}$ concentration in response to SWAP $(p<0.05)$ and SEA stimulation $(p<$ $0.01)$, however lower concentration of HES $(50 \mu \mathrm{M})$ not significantly $(p>0.05)$ altered IL-12 production in response
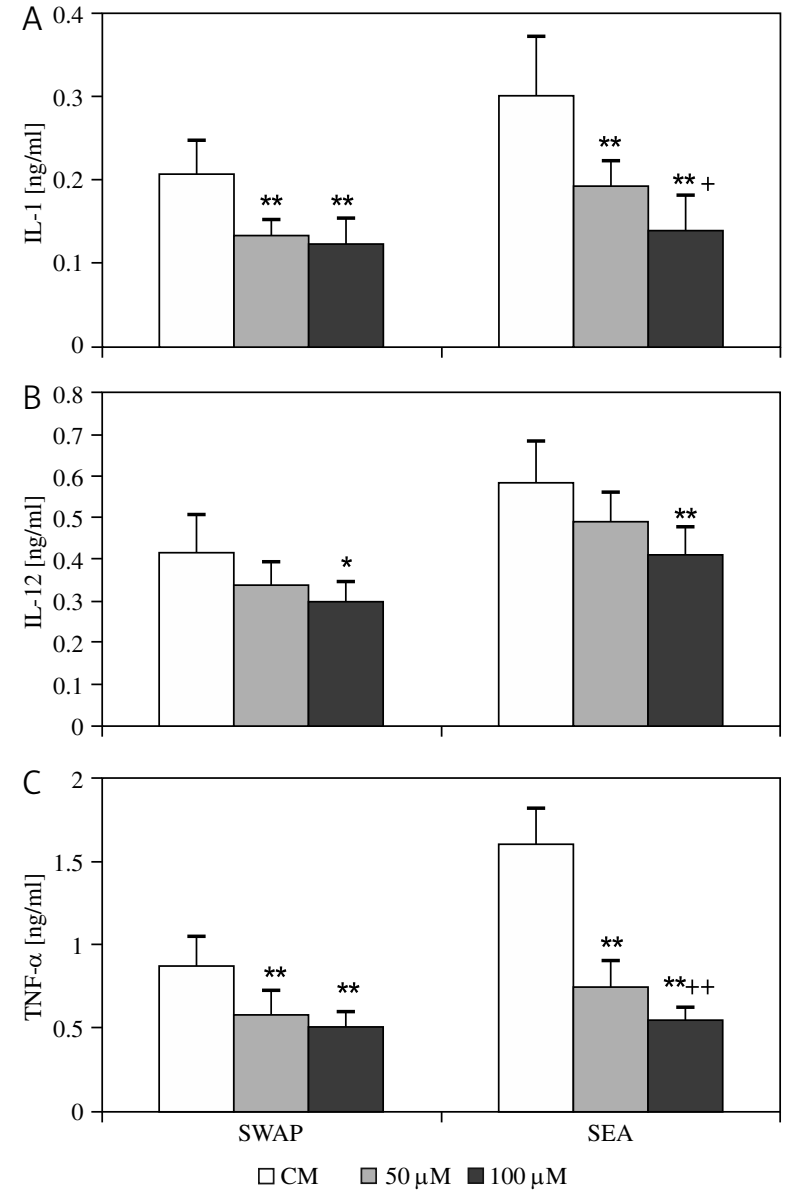

Fig. 3. The effect of hesperidin on IL-1 $\beta$ (A), IL-12 (B), and TNF- $\alpha(C)$ production in response to SWAP and SEA stimulation. Columns represent mean of 5 individual mice, and the bars denote SD about the mean. Significant differences between culture medium (CM) and HES are denoted by asterisks $(* p<0.05, * * p<0.01)$ and between HES concentrations by plus $\left({ }^{+} p<0.05,{ }^{++} p<0.01\right)$ above the columns

to either SWAP or SEA stimulation (Fig. 3B). Indeed, IL-12 involved in differentiation of naive CD4+ lymphocyte to Th1 subset [79]. Several studies suggested that IL-12 possessed a role in the protective immunity against $S$. mansoni $[16,18,80]$, however, IL-12 had no effect on immunity when administered alone during a normal infection [17]. Moreover, IL-12 deficient mice showed a substantial reduction in the level of protection induced by attenuated larvae [20]. On the other hand, IL-12 might have a role in regulation of granuloma formation, as mice vaccinated with SEA plus IL-12 developed smaller granulomas and less-severe fibrosis in the subsequent infection [60].

Our data clearly showed that HES highly significantly $(p<0.01)$ decreased TNF- $\alpha$ production in response to SWAP and SEA in a dose dependent manner (Fig. 3C). The pathology associated with schistosomiasis was largely attrib- 
uted to the intense granulomatous reactions and subsequent fibrosis induced by parasite eggs that become trapped in host organs such as the liver and intestine. Currently, it is well documented that TNF- $\alpha$ plays an important role in granulomatous inflammation. It restored the ability of $\mathrm{T}$ cell deficient mice to mount a granuloma around schistosome eggs [81]; and caused tissue damage by the exacerbation of the granuloma formation and overproduction of reactive oxygen species [82]. Therefore, downregulation of TNF- $\alpha$ could largely reduce pathology associated with schistosomiasis [83].

\section{Conclusions}

From aforementioned data, HES up regulated IL-4, IL-10, and IFN- $\gamma$ secretion; and down regulated IL-1, IL-12, IL-13, IL-17, and TNF- $\alpha$ production from splenocytes of 8 weeks $S$. mansoni infected mice. This preferentially modulation of cytokine production could reduce immunopathology of schistosomiasis. The precise mechanism by which HES regulated production of these cytokines was unclear and needs further investigations, however, HES has been shown to reduce IL-5 production in experimental ovalbumin-induced asthma model via inhibition of GATA-3 transcription factor [53]. Therefore, HES might modulate cytokine production through regulation of transcription factors such as c-maf, GATA-3, NFAT, and STAT6.

This work was supported by a grant number: 1-4331571, Taif University, Ministry of Higher Education, Saudi Arabia.

The authors declare no conflict of interest.

\section{References}

1. Pearce EJ, MacDonald AS (2002): The immunobiology of schistosomiasis. Nat Rev Immunol 2: 499-511.

2. Warren KS, Domingo EO, Cowan RBT (1967): Granuloma formation around schistosome eggs as a manifestation of delayed hypersensitivity. Am J Pathol 51: 735-756.

3. Hernandez HJ, Wang Y, Tzellas N, et al. (1997): Expression of class II, but not class I, major histocompatibility complex molecules is required for granuloma formation in infection with Schistosoma mansoni. Eur J Immunol 27: 1170-1176.

4. Yu L, Sun X, Yang F, et al. (2012): Inflammatory cytokines IFN- $\gamma$, IL-4, IL-13 and TNF- $\alpha$ alterations in schistosomiasis: a meta-analysis. Parasitol Res 110: 1547-1552.

5. O'Garra A (1998): Cytokines induce the development of functionally heterogeneous $\mathrm{T}$ helper cell subsets. Immunity 8: 275283.

6. Seder RA, Paul WE (1994): Acquisition of lymphokine-producing phenotype by CD4+ T cells. Annu Rev Immunol 12: 635-763.

7. Szabo SJ, Dighe AS, Gubler U, et al. (1997): Regulation of the interleukin (IL)-12R beta 2 subunit expression in developing $\mathrm{T}$ helper 1 (Th1) and Th2 cells. J Exp Med 185: 817-824.
8. Mountford AP, Coulson PS, Sher AW, Cheever A, et al. (1999): Interleukin-12 can directly induce T-helper 1 responses in interferon-gamma (IFN-gamma) receptor-deficient mice, but requires IFN-gamma signalling to downregulate T-helper 2 responses. Immunol 97: 588-594.

9. Grzych JM, Pearce EJ, Cheever A, et al. (1991): Egg deposition is the major stimulus for the production of Th2 cytokines in murine Schistosomiasis mansoni. J Immunol 146: 1322-1327.

10. Wynn TA, Cheever AW, Williams ME, et al. (1998): IL-10 regulates liver pathology in acute murine schistosomiasis mansoni but is not required for immune down-modulation of chronic disease. J Immunol 160: 4473-4480.

11. Kaplan MH, Whitfield JR, Boros DL, et al. (1998): Th2 cells are required for the Schistosoma mansoni egg-induced granulomatous response. J Immunol 160: 1850-1856.

12. Jankovic D, Kullberg MC, Noben-Trauth N, et al. (1999): Schistosome-infected IL-4 receptor knockout (KO) mice, in contrast to IL-4 KO mice, fail to develop granulomatous pathology while maintaining the same lymphokine expression profile. J Immunol 163: 337-342.

13. Fallon PG, Richardson EJ, McKenzie GJ, et al. (2000): Schistosome infection of transgenic mice defines distinct and contrasting pathogenic roles for IL-4 and IL-13: IL-13 is a profibrotic agent. J Immunol 164: 2585-2591.

14. Fallon PG, Dunne DW (1999): Tolerization of mice to Schistosoma mansoni egg antigens causes elevated type 1 and diminished type 2 cytokine responses and increased mortality in acute infection. J Immunol 162: 4122-4132.

15. Zhou S, Liu S, Song G, et al. (2000): Protective immunity induced by the full-length cDNA encoding paramyosin of Chinese Schistosoma japonicum. Vaccine 18: 3196-3204.

16. Fonseca CT, Brito CF, Alves JB, et al. (2004): IL-12 enhances protective immunity in mice engendered by immunization with recombinant $14 \mathrm{kDa}$ Schistosoma mansoni fatty acid-binding protein through an IFN-gamma and TNF-alpha dependent pathway. Vaccine 22: 503-510.

17. Wynn TA, Jankovic D, Hieny S, et al. (1995): IL-12 enhances vaccine-induced immunity to Schistosoma mansoni in mice and decreases T helper 2 cytokine expression, $\operatorname{IgE}$ production, and tissue eosinophilia. J Immunol 154: 4701-4709.

18. Wynn TA, Reynolds A, James SL, et al. (1996): IL-12 enhances vaccine-induced immunity to schistosomes by augmenting both humoral and cell-mediated immune responses against the parasite. J Immunol 157: 4068-4078.

19. Mountford AP, Pearlman E (1998): Interleukin-12 and the host response to parasitic helminths; the paradoxical effect on protective immunity and immunopathology. Parasit Immunol 20: 509-517.

20. Anderson S, Shires VL, Wilson RA, et al. (1998): In the absence of IL-12, the induction of Th1-mediated protective immunity by the attenuated schistosome vaccine is impaired, revealing an alternative pathway with Th2-type characteristics. Eur J Immunol 28: 2827-2838.

21. Anderson S, Shires VL, Wilson RA, et al. (1999): Formation of multinucleated giant cells in the mouse lung is promoted in the absence of interleukin-12. Am J Respir Cell Mol Biol 20: 371-378.

22. El Ridi R, Tallima H, Salah M, et al. (2009): Transforming growth factor-beta and Th17 responses in resistance to primary murine schistosomiasis mansoni. Cytokine 48: 239-245.

23. Park H, Li Z, Yang XO, et al. (2005): A distinct lineage of CD4 $\mathrm{T}$ cells regulates tissue inflammation by producing interleukin 17. Nat Immunol 6: 1133-1141. 
24. Harrington LE, Hatton RD, Mangan PR, et al. (2005): Interleukin 17-producing CD4+ effector T cells develop via a lineage distinct from the $\mathrm{T}$ helper type 1 and 2 lineages. Nat Immunol 6: 1123-1132.

25. Nakae S, Nambu A, Sudo K, et al. (2003): Suppression of immune induction of collagen-induced arthritis in IL-17deficient mice. J Immunol 171: 6173-6177.

26. Langrish CL, Chen Y, Blumenschein WM, et al. (2005): IL23 drives a pathogenic $T$ cell population that induces autoimmune inflammation. J Exp Med 201: 233-240.

27. Chen Y, Langrish CL, McKenzie B, et al. (2006): Anti-IL-23 therapy inhibits multiple inflammatory pathways and ameliorates autoimmune encephalomyelitis. J Clin Invest 116: 13171326.

28. Yen D, Cheung J, Scheerens H, et al. (2006): IL-23 is essential for $\mathrm{T}$ cell-mediated colitis and promotes inflammation via IL-17 and IL-6. J Clin Invest 116: 1310-1316.

29. Rutitzky LI, da Rosa LJ, Stadecker MJ (2005): Severe CD4 T cell-mediated immunopathology in murine schistosomiasis is dependent on IL-12p40 and correlates with high levels of IL-17. J Immunol 175: 3920-3926.

30. Rutitzky LI, Bazzone L, Shainheit MG, et al. (2008): IL-23 is required for the development of severe egg induced immunopathology in schistosomiasis and for lesional expression of IL-17. J Immunol 180: 2486-2495.

31. Shainheit MG, Smith PM, Bazzone LE, et al. (2008): Dendritic cell IL-23 and IL-1 production in response to schistosome eggs induces Th17 cells in a mouse strain prone to severe immunopathology. J Immunol 181: 8559-8567.

32. Pearce EJ, Kane M, Sun CJ, et al. (2004): Th2 response polarization during infection with the helminth parasite Schistosoma mansoni. Immunol Rev 201: 117-126.

33. Hesse M, Piccirillo CA, Belkaid Y, et al. (2004): The pathogenesis of schistosomiasis is controlled by cooperating IL-10producing innate effector and regulatory T cells. J Immunol 172: 3157-3166.

34. Taylor JJ, Mohrs M, Pearce EJ (2006): Regulatory T cell responses develop in parallel to $\mathrm{Th}$ responses and control the magnitude and phenotype of the Th effector population. J Immunol 176: 5839-5847.

35. Wacker A, Eilmes HG (1975): Virus inhibition using hesperidin. Naturwissenschaften 62: 301.

36. Galati EM, Monforte MT, Kirjavainen S, et al. (1994): Biological effects of hesperidin, a citrus flavonoid (Note I): antiinflammatory and analgesic activity. Farmacol 40: 709-712.

37. Patil JR, Murthy KNC, Jayaprakasha GK, et al. (2009): Bioactive compounds from Mexican lime (Citrus aurantifolia) juice induce apoptosis in human pancreatic cells. J Agric Food Chem 57: 10933-10942.

38. Pałgan K, Bartuzi Z (2011): The role of flavonoids in asthma. Post Dermatol Alergol 28: 396-401.

39. Zielinska-Przyjemska M, Ignatowicz E (2008): Citrus fruit flavonoids influence on neutrophil apoptosis and oxidative metabolism. Phytother Res 22: 1557-1562.

40. Park HJ, Kim MJ, Ha E, et al. (2008): Apoptotic effect of hesperidin through caspase 3 activation in human colon cancer cells, SNU-C4. Phytomedicine 15: 147-151.

41. Vinson JA, Liang X, Proch J, et al. (2002): Polyphenol antioxidants in citrus juices: in vitro and in vivo studies relevant to heart disease. Adv Exp Med Biol 505: 113-122.

42. Wilmsen PK, Spada DS, Salvador M (2005): Antioxidant activity of the flavonoid hesperidin in chemical and biological systems. J Agric Food Chem 53: 4757-4761.
43. Sakata K, Hirose Y, Qiao Z, et al. (2003): Inhibition of inducible isoforms of cyclooxygenase and nitric oxide synthase by flavonoid hesperidin in mouse macrophage cell line. Cancer Lett 199: 139-145.

44. Choi YJ, Kang JS, Park JH, et al. (2003): Polyphenolic flavonoids differ in their antiapoptotic efficacy in hydrogen peroxide-treated human vascular endothelial cells. J Nutr 133: 985-991.

45. Kang SR, Han DY, Park KI, et al. (2011): Suppressive effect on lipopolysaccharide-induced proinflammatory mediators by Citrus aurantium L. in macrophage RAW 264.7 cells via NF$\kappa \mathrm{B}$ signal pathway. Evid Based Complement Alternat Med 2011 pii: 248592.

46. Kang SR, Park K, Park HS, et al. (2011): Anti-inflammatory effect of flavonoids isolated from Korea Citrus aurantium L. on lipopolysaccharide-induced mouse macrophage RAW 264.7 cells by blocking of nuclear factor-kappa $\mathrm{B}$ (NF- $\mathrm{KB}$ ) and mitogen-activated protein kinase (MAPK) signalling pathways. Food Chem 129: 1721-1728.

47. Kawaguchi K, Kikuchi S, Hasunuma R, et al. (2004): A citrus flavonoid hesperidin suppresses infection induced endotoxin shock in mice. Biol Pharm Bull 27: 679-683.

48. Yeh CC, Kao SJ, Lin CC, et al. (2007): The immunomodulation of endotoxin-induced acute lung injury by hesperidin in vivo and in vitro. Life Sci 80: 1821-1831.

49. Choi IY, Kim SJ, Jeong HJ, et al. (2007): Hesperidin inhibits expression of hypoxia inducible factor- 1 alpha and inflammatory cytokine production from mast cells. Mol Cell Biochem 305: 153-161.

50. Xu L, Yang ZL, Li P, et al. (2009): Modulating effect of hesperidin on experimental murine colitis induced by dextran sulfate sodium. Phytomedicine 16: 989-995.

51. Lee YR, Jung JH, Kim HS (2011): Hesperidin partially restores impaired immune and nutritional function in irradiated mice. J Med Food 14: 475-482.

52. Raza SS, Khan MM, Ahmad A, et al. (2011): Hesperidin ameliorates functional and histological outcome and reduces neuroinflammation in experimental stroke. Brain Res 1420: 93-105.

53. Kim SH, Kim BK, Lee YC (2011): Antiasthmatic effects of hesperidin, a potential $\mathrm{Th} 2$ cytokine antagonist, in a mouse model of allergic asthma. Mediators Inflamm 2011: 485402.

54. Ok IS, Kim SH, Kim BK, et al. (2009): Pinellia ternata, Citrus reticulata, and their combinational prescription inhibit eosinophil infiltration and airway hyper-responsiveness by suppressing CCR $3+$ and $\mathrm{Th} 2$ cytokines production in the ovalbumin-induced asthma model. Mediators Inflamm 2009: 413270.

55. Tanabe S, Kinuta Y, Yasumatsu H, et al. (2007): Effects of Citrus unshiupowder on the cytokine balance in peripheral blood mononuclear cells of patients with seasonal allergic rhinitis to pollen. Biosci Biotechnol Biochem 7: 2852-2855.

56. Schubert M (1948): Conditions for drug testing in experimental Schistosomiasis mansoni in mice. Am J Trop Med 28: 121-136.

57. Bruce JI, Radke MG (1971): Culturing Biomphalaria and Oncomelania (Gastropoda) for large-scale studies of schistosomiasis. I. Cultivation of Biomphalaria glabrata and maintenance of Schistosoma mansoni in the laboratory. Biomed Rep 406th Med Lab 19: 1-84.

58. Lowry OH, Rosenbrough NJ, Farr AL, et al. (1951): Protein measurement with Folin-Phenol reagent. J Biol Chem 193: 265-275.

59. Fallon PG, Smith P, Dunne DW (1998): Type 1 and type 2 cytokine producing mouse CD4+ and CD8+ T cells in acute Schistosoma mansoni infection. Eur J Immunol 28: 1408-1416. 
60. Cheever AW, Yap GS (1997): Immunologic basis of disease and disease regulation in schistosomiasis. Chem Immunol 66: 159-176.

61. Brunet LR, Finkelman FD, Cheever AW, et al. (1997): IL-4 protects against TNF-alpha-mediated cachexia and death during acute schistosomiasis. J Immunol 159: 777-785.

62. Moore KW, O'Garra A, Malefyt RW, et al. (1993): Interleukin10.Annu Rev Immunol 11: 165-190.

63. Hoffmann KF, Cheever AW, Wynn TA (2000): IL-10 and the dangers of immune polarization, excessive type 1 and type 2 cytokine responses induce distinct forms of lethal immunopathology in murine schistosomiasis. J Immunol 164: 6406-6416.

64. LaFlamme AC, Patton EA, Bauman B, et al. (2001): IL-4 plays a crucial role in regulating oxidative damage in liver during Schistosomiasis. J Immunol 166: 1903-1911.

65. Brunet LR, Dunne DW, Pearce EJ (1998): Cytokine interaction and immune responses during Schistosoma mansoni infection. Parasitol Today 14: 422-427.

66. Chiaramonte MG, Cheever AW, Malley JD, et al. (2001): Studies of murine schistosomiasis reveal interleukin-13 blockade as a treatment for established and progressive liver fibrosis. Hepatol 34: 273-282.

67. de Jesus AR, Magalhães A, Miranda DG, et al. (2004): Association of type 2 cytokines with hepatic fibrosis in human Schistosoma mansoni infection. Infect Immun 72: 3391-3397.

68. Chiaramonte MG, Donaldson DD, Cheever AW, et al. (1999): An IL-13 inhibitor blocks the development of hepatic fibrosis during a T-helper type 2-dominated inflammatory response. J Clin Invest 104: 777-785.

69. Kaviratne M, Hesse M, Leusink M, et al. (2004): IL-13 activates a mechanism of tissue fibrosis that is completely TGFbeta independent. J Immunol 173: 4020-4029.

70. Nworu CS, Akah PA, Okoye FB, et al. (2012): Supplementation with aqueous leaf extract of Morinda lucida enhances immunorestoration and upregulates the expression of cytokines and immunostimulatory markers. Immunol Invest 41: 799-819.

71. Wynn TA, Oswald IP, Eltoum IA, et al. (1994): Elevated expression of Th1 cytokines and nitric oxide synthase in the lung of vaccinated mice after challenge infection with Schistosomiasis mansoni. J Immunol 153: 5200-5209.

72. Oswald IP, Eltoum I, Wynn TA, et al. (1994): Endothelial cells are activated by cytokine treatment to kill an intravascular parasite, Schistosoma mansoni, through the production nitric oxide. Proc Natl Acad Sci U S A 91: 999-1003.

73. Doenhoff MJ (1997): A role for granulomatous inflammation in the transmission of infectious disease: schistosomiasis and tuberculosis. Parasitol 115: 113-125.

74. Silva L, Fernandes A, Barbosa A, et al. (2000): Significance of Schistosomal granuloma modulation. Mem Inst Oswaldo Cruz 95: 353-361.

75. Czaja MJ, Weiner FR, Takahashi S, et al. (1989): Gammainterferon treatment inhibits collagen deposition in murine schistosomiasis. Hepatol 10: 795-800.

76. Dinarello CA (1994): The biological properties of interleukin1. Eur Cytokine Netw 5: 517-531.

77. Krakauer T, Vilcek J, Oppenheim JJ (1999): Proinflammatory cytokines TNF and IL-1 families, chemokines, TGF- $\beta$, and others. In: Fundamental immunology. Paul WE (ed.). Lippincott-Raven, Philadelphia, 775-811.

78. El Ridi R, Wagih A, Salem R, et al. (2006): Impact of interleukin-1 and interleukin- 6 in murine primary schistosomiasis. Int Immunopharmacol 6: 1100-1108.
79. Abbas AK, Murphy KM, Sher A (1996): Functional diversity of helper T lymphocytes. Nature 383: 787-793.

80. Wynn TA, Reynolds A, James S, et al. (1996): IL-12 enhances vaccine-induced immunity to schistosomes by augmenting both humoral and cell-mediated immune responses against the parasite. J Immunol 157: 4068-4078.

81. Amiri P, Locksley RM, Parslow TG, et al. (1992): Tumour necrosis factor alpha restores granulomas and induces parasite egg-laying in schistosome-infected SCID mice. Nature 356: 604-607.

82. Gharib B, Abdallahi OM, Dessein H, et al. (1999): Development of eosinophil peroxidase activity and concomitant alteration of the antioxidant defenses in the liver of mice infected with Schistosoma mansoni. J Hepatol 30: 594-602.

83. Allam G (2009): Immunomodulatory effects of curcumin treatment on murine schistosomiasis mansoni. Immunobiol 214: 712-727. 